\title{
Treatment expectations and patient-reported outcomes of nusinersen therapy in adult spinal muscular atrophy
}

\author{
Alma Osmanovic ${ }^{1}$. Gresa Ranxha ${ }^{1}$ Mareike Kumpe ${ }^{1}$ - Lars Müschen ${ }^{1} \cdot$ Camilla Binz ${ }^{1} \cdot$ Flavia Wiehler $^{1}$. \\ Lejla Paracka $^{1}$. Sonja Körner ${ }^{1} \cdot$ Katja Kollewe $^{1}$ - Susanne Petri ${ }^{1} \cdot$ Olivia Schreiber-Katz $^{1}$
}

Received: 19 December 2019 / Revised: 14 April 2020 / Accepted: 17 April 2020 / Published online: 2 May 2020

(c) The Author(s) 2020

\begin{abstract}
Background The antisense-oligonucleotide (ASO) nusinersen has recently been approved as the first genetically modifying therapy for 5q-associated spinal muscular atrophy (SMA) based on randomized sham-controlled trials in infants and children. The efficacy in adults with long disease history and advanced disease status is still widely unknown; the same applies to specific expectations of adult SMA patients and to what extent they are met and may impact outcome measures.

Methods In a longitudinal monocentric study in adult patients with SMA types 2-4, the Stanford Expectations of Treatment Scale (SETS) was assessed prior to and during nusinersen treatment. Treatment outcome was evaluated using patient-reported outcomes (PROs) as well as objectively quantifiable motor outcome measures.

Results Adult SMA patients had high expectations of nusinersen treatment effectiveness regarding increase in muscle strength and disease stabilization. Via PROs, 75\% stated improvements in muscle strength, endurance and independence under therapy which was in line with slight improvements in quantifiable motor scores during a ten month observation period. In contrast, patients only expressed few negative expectations which further decreased during therapy.

Conclusions This study showed mainly positive treatment expectations and PROs in patients undergoing nusinersen treatment along with measurable functional improvement in adult SMA patients. Moreover, treatment expectations did not significantly influence outcome measures.
\end{abstract}

Keywords Spinal muscular atrophy $(\mathrm{SMA}) \cdot$ Patient-reported outcomes $(\mathrm{PROs}) \cdot$ Stanford expectations of treatment scale $(\mathrm{SETS}) \cdot$ Nusinersen $\cdot$ Antisense-oligonucleotide (ASO)

Alma Osmanovic and Gresa Ranxha: These authors contributed equally as first authors to the manuscript.

Susanne Petri and Olivia Schreiber-Katz: These authors contributed equally as senior authors to the manuscript.

Electronic supplementary material The online version of this article (https://doi.org/10.1007/s00415-020-09847-8) contains supplementary material, which is available to authorized users.

$\triangle$ Alma Osmanovic

Osmanovic.Alma@mh-hannover.de

1 Department of Neurology, Hannover Medical School, Carl-Neuberg-Strasse 1, 30625 Hannover, Germany

\section{Introduction}

Spinal muscular atrophy (SMA), a neuromuscular disorder with autosomal-recessive inheritance and the most common genetic cause of infant mortality, recently gained increased attention due to the approval of nusinersen, the first drug for treatment of SMA [1]. SMA is characterized by progressive degeneration of alpha motor neurons leading to progressive, disabling skeletal muscle weakness with scoliosis, respiratory insufficiency and reduced life expectancy. Patients are classified in different phenotypes depending on the age of symptom onset and the best motor milestone reached within the individual development (types 0-4) [2]. Herein, types 0 and 1 mark the most severe congenital/infantile SMA types, so far mostly lethal within the first years. SMA type 2 and 3 patients reach adulthood with a heterogeneous degree of motor function impairment. SMA type 2 patients manifest within the first 18 months of age. Approximately $70 \%$ of 
SMA 2 cases survive over 25 years, in the majority with a severe phenotype. SMA type 3 patients show a more variable phenotype. They acquire the ability to walk but may lose it during disease progression. Life expectancy is usually normal. The rare SMA 4 phenotype is characterized by adult-onset and overall milder condition [3, 4].

The main genetic cause of SMA (in > 95\%) are homozygous deletions in the SMN1 (survival of motor neuron) gene, resulting in a decreased expression of SMN protein, an essential protein for motor neuron maintenance [5]. An almost identical gene, $S M N 2$, is present in multiple copies in the human genome. Due to impaired pre-mRNA splicing, $S M N 2$ produces only a small amount of intact SMN protein. A higher copy number of $S M N 2$ is related to a milder SMA phenotype and vice versa $[5,6]$. Nusinersen, which specifically modifies $S M N 2$ splicing, has been approved for the treatment of all SMA subtypes based on two double-blind, sham-controlled, phase 3 studies conducted in infants and children up to nine years of age at the time of enrollment into the trial [7, 8]. Significant improvement of motor function by nusinersen treatment was demonstrated in both trials. Nusinersen, an antisense-oligonucleotide (ASO), does not cross the blood-brain barrier [9]. Therefore, the administration is performed by intrathecal injections following a standard treatment regime, which encompasses initial loading doses on days $0,14,28$ and 63 followed by maintenance therapy in 4-monthly intervals, as established in an open-label, phase 2 dose-escalating clinical study [10].

In adult SMA patients, controlled studies in larger patients groups assessing the efficacy of nusinersen with suitable outcome measures have not been conducted. A recently published observational study in a large cohort of nusinersen treated adults demonstrated significant improvements in the Hammersmith Functional Motor Scale Expanded (HFMSE) under nusinersen treatment [11]. Because of floor and ceiling effects in commonly used motor scores, and for monitoring of changes in motor-related symptoms such as ventilation and swallowing, patient-reported outcomes (PROs) have been discussed as an important additional outcome to assess treatment efficacy, especially in severely affected adult patients, in which common motor function tests are not applicable [11, 12]. However, patients' individual outcome expectations of a specific treatment have been shown to influence treatment response, known as placebo effect $[13,14]$. Sham-controlled efficacy trials in adult SMA patients are not feasible due to ethical reasons in respect of the unlimited approval of nusinersen. Patients' expectations and self-reported outcomes under nusinersen treatment have not been studied yet. We aimed to evaluate adult patients' expectations before and during nusinersen therapy, individually reported and quantitative outcome parameters and the relation between both in a prospective monocentric study.

\section{Methods}

\section{Patients and clinical evaluation}

We enrolled adult SMA patients aged 18 years and above treated with nusinersen at the Hannover Medical School between 2017 and 2019. The study has been approved by the local ethics review board. All patients gave their written informed consent before entering the study. A genetically confirmed diagnosis of SMA (homozygous deletion of exon 7 (or/ and exon 8) of $S M N I$ ) was available for all patients prior to the initiation of treatment. Nusinersen was administered intrathecally (12 $\mathrm{mg}$ in $5 \mathrm{ml}$ ) in compliance with the recommended application scheme. Study enrollment took place either before or during treatment with nusinersen. Specific further baseline characteristics of all nusinersen treated patients were recorded, which included age, symptom onset, disease duration, SMN2 copy number, SMA type, the ability to walk, presence of scoliosis, the need for non-invasive ventilation or a feeding tube and baseline muscle function impairment. The body mass index (BMI) was determined once at baseline. Muscle function was routinely assessed by professional therapists using the Revised Upper Limb Module (RULM) score [15] and the Hammersmith Functional Motor Scale Expanded (HFMSE) [16]. RULM has 20 items with a maximum of 37 points, higher scores indicating better upper limb function. The HFMSE is a validated 33 item scoring tool specifically for use in SMA patients. Each item is scored on a scale from 0 to 2, with a total of up to 66 points.

\section{Patient-reported decision-making process and treatment expectations}

Patients were asked about their therapy decision-making process and they completed the Stanford expectations of treatment scale (SETS), a validated tool for measuring patients' expectations regarding the outcome of a novel treatment, before and during nusinersen therapy. Each of the six items is coded with the same 7-point scale, starting from "I strongly disagree" up to "I strongly agree" [17]. Three items address positive (effectiveness, cure, confidence) and three items address negative (worries, fears, nervousness about negative effects) treatment expectations, respectively. Moreover, patients were asked to report their individual (positive and negative) expectations, which were summed up into reasonable categories afterwards. Longitudinal and cross-sectional analyses were performed.

\section{Patient-reported outcomes}

Based on patient-reported expectations, we used a selfdesigned questionnaire to assess individual self-rated improvement and worsening during the therapy. Patients 
had to indicate improvement ordeterioration of 18 conditions compared to their medical condition before nusinersen treatment (supplementary material S1). An additional free-text option was provided. For analysis, each item was scored with one point, counted only once and visualized in a sum score as either improvement or worsening. Items in which significant treatment effects had been reported were identified afterwards and grouped into six main categories, named "muscle strength", "endurance", "independence", "mobility", "bulbar function", "respiratory function", further items were listed under "miscellaneous ". Patients also had the option to state that "nothing improved" or "nothing worsened".

\section{Statistical analysis}

Statistical analysis was performed using IBM SPSS Statistics $20 \circledR$ software. Differences between groups were analyzed by t-test or chi-square-test with a significance level of $p<0.05$. Correlations were performed with Pearson or Spearman correlation. Univariate linear regression model analysis was performed if suitable.

\section{Results}

\section{Patient characterization}

24 adult SMA patients (nine females and 15 males) were enrolled into this study either at the start of $(n=16)$ or during nusinersen treatment $(n=8)$ with a mean age of 38.9 years and a mean disease duration of 31.1 years (Table 1). One SMA type 4 patient was further evaluated together with SMA type 3 patients. Ten patients were ambulatory, while another ten had a scoliosis and six needed a (part-time) noninvasive ventilation. The mean baseline motor scores were 23.2/66 for the HFMSE and 20/37 for the RULM score, both with a wide range which, altogether, reflects the various phenotypes and disease progression stages of the enrolled patients. Two SMA type 3 patients discontinued nusinersen treatment due to disease progression during the therapy, which was subjectively apparent and also confirmed by a decrease in motor scores. Side effects were reported in $96 \%$ ( $89 \%$ of SMA type 2 and $100 \%$ of type $3 / 4$ patients) which were mainly related to the procedure of intrathecal administration (88\%) like back pain and headache (Table 1).

\section{Treatment information, decision-making and reasons for delay}

We did not actively contact SMA patients to inform them on the approval of a new treatment. Our patients named the national patient registry (http://www.sma-register.de) [18]
Table 1 Characteristics of enrolled patients

\begin{tabular}{|c|c|c|c|}
\hline$N=24$ & $N(\%)$ & Mean (SD) & Range \\
\hline Women & $9(38)$ & & \\
\hline Age (y) & & $38.9(13.5)$ & $19.8-65.4$ \\
\hline Age at therapy start (y) & & $37.9(13.4)$ & $19-64.4$ \\
\hline Symptom onset (y) & & $6.8(10.1)$ & $0.5-47.2$ \\
\hline Disease duration (y) & & $31.1(14.2)$ & $2.2-62.1$ \\
\hline BMI & & $21.57(6.1)$ & $8.5-35.9$ \\
\hline \multicolumn{4}{|l|}{$S M N 2$ copy number } \\
\hline 2 & $2(8)$ & & \\
\hline 3 & $10(42)$ & & \\
\hline 4 & $9(38)$ & & \\
\hline 5 & $1(4)$ & & \\
\hline 6 & $2(8)$ & & \\
\hline \multicolumn{4}{|l|}{ SMA type } \\
\hline Type 2 & $9(38)$ & & \\
\hline Type 3 & $14(58)$ & & \\
\hline Type 4 & $1(4)$ & & \\
\hline Ambulatory & $10(42)$ & & \\
\hline Scoliosis & $10(42)$ & & \\
\hline Ventilation & $6(25)$ & & \\
\hline Feeding tube & $2(8)$ & & \\
\hline \multicolumn{4}{|l|}{ Motor function scores } \\
\hline HFMSE (max. 66) & & $23.2(25.1)$ & $0-64$ \\
\hline RULM (max. 37) & & $20(12.8)$ & $0-37$ \\
\hline \multicolumn{4}{|c|}{ Treatment duration at analysis } \\
\hline 6 months & $7(29)$ & & \\
\hline 10 months & $9(38)$ & & \\
\hline 14 months & $5(21)$ & & \\
\hline 18 months & $3(13)$ & & \\
\hline \multicolumn{4}{|l|}{ Patient enrollment } \\
\hline At therapy start & $16(67)$ & & \\
\hline During therapy & $8(33)$ & & \\
\hline \multicolumn{4}{|l|}{ Side effects } \\
\hline \multicolumn{4}{|l|}{ Administration-related } \\
\hline Back pain & $15(63)$ & & \\
\hline Headache & $14(58)$ & & \\
\hline Nausea & $4(17)$ & & \\
\hline Vertigo & $3(13)$ & & \\
\hline \multicolumn{4}{|l|}{ Not Administration-related } \\
\hline Constipation & $2(8)$ & & \\
\hline Upper airway infection & $2(8)$ & & \\
\hline Tachycardia & $1(4)$ & & \\
\hline
\end{tabular}

HFMSE Hammersmith Functional Motor Scale Expanded, max. maximum, $N$ number, RULM Revised Upper Limb Module, $S D$ standard deviation, SMN2 survival motor neuron 2 gene, $y$ years

as the main information source (31\% of enrolled patients) followed by information through friends (19\%) and physicians (general practitioners, neurologists and others; $16 \%$ ). Despite the awareness of nusinersen being the first drug to 
treat their condition, nearly 50\% did not immediately opt for the treatment. The reasons were pending specialized medi$\mathrm{cal} /$ neurologist consultations (58\%), own research (42\%), private circumstances and fears of side effects (each 33\%). In addition, uncertainty concerning study results and the administration procedure were stated (each by $25 \%$ ) as reasons for decision delay.

Prior to treatment initiation, all patients presented at least once in our neuromuscular outpatient clinic. In this setting, they were informed about the results of the clinical trials ENDEAR and CHERISH with beneficial outcomes in children, adverse events (low platelet count, kidney disease, and hydrocephalus) and the administration procedure via lumbar puncture and its risks.

\section{Patient-reported treatment expectations}

23 of 24 SMA patients (SMA type $2 n=8$, type $3 / 4 n=15$ ) completed the SETS questionnaire within the first year of treatment (Fig. 1a). Regarding positive expectations, $83 \%$ of patients expected effectiveness of nusinersen treatment and $83 \%$ stated to have complete confidence in this treatment. However, the majority of patients $(91 \%)$ did not expect that the condition would be completely cured after the treatment. There were considerably less negative expectations: Only $22 \%$ of patients had worries, $30 \%$ expressed fears and $26 \%$ indicated to be nervous about negative effects of this treatment. No significant differences between SMA types were detected.

Specific individual expectations and therapeutic goals were obtained from all 24 SMA patients. $88 \%$ of the reported expectations could be summarized in seven categories (Fig. 1b). The majority of patients hoped for beneficial effects on muscle strength $(79 \%)$ and disease stabilization (54\%), followed by increased mobility, endurance and independence. An improvement in bulbar function was only expected by $4 \%$, which only applied to SMA type 2 patients. Moreover, only $8 \%$ expected to be cured entirely (only SMA type 3 patients). Further expectations were only stated once or twice and therefore negligible (general improvements, facilitation in everyday life, improvement of mental health, support of SMA research and use of regular cutlery).

A subgroup of 14 SMA patients completed the SETS before therapy initiation. Pre-treatment expectation of nusinersen effectiveness was high and remained stable during the therapeutic course with no significant differences over time (Fig. 1c). However, major changes in negative expectations, such as nervousness about negative effects of nusinersen were seen during therapy. Pre-treatment nervousness notably decreased within the first year of nusinersen treatment (Fig. 1d).

Correlation analysis of pre-treatment expectation of effectiveness of nusinersen and age $(p=0.236)$, disease duration
( $p=0.615)$, SMA type $(p=0.634)$, and disease severity (HFMSE $p=0.887$, RULM $p=0.793$ ) showed no significant relation. However, pre-treatment expectation of a cure of SMA by nusinersen revealed a significant correlation with baseline items of disease severity (HFMSE $p=0.029$; RULM $p=0.035$; SMN2 copy number $>4 p=0.030$ ). Regression analysis confirmed the relationship between the HFMSE score and pre-treatment expectation of a complete cure of the disease $\left(R^{2}=0.3402\right)$ (Fig. 1e). Patients with a milder phenotype (thus higher SMN2 copy numbers, higher HFMSE and RULM scores) indicated greater expectation of a cure of their condition by nusinersen treatment. A significant correlation between disease duration and negative expectations (worries $p=0.003$, fears $p=0.04$ and nervousness about negative effects $p=0.021$ ) was observed. Regression analysis indicated a linear relationship between disease duration and worries about the therapy $\left(R^{2}=0.5334\right)$ (Fig. 1f). Patients with longer disease duration indicated more negative expectations when asked before treatment initiation. This relationship disappeared within the first year of treatment, as negative treatment expectations considerably decreased during treatment.

\section{Patient-reported and motor outcomes}

Three patients (13\%) reported disease stabilization, which means neither improvement nor worsening, whereas $75 \%$ stated improvement during a follow-up of ten months under nusinersen treatment (Fig. 2a). An increase of muscle strength in either legs, arms, trunk or in general was more often reported in less severely affected patients (87\% of SMA $3 / 4$ vs. $33 \%$ of SMA 2) (Fig. 2b). In contrast, improvement of endurance, independence and mobility did not show specific differences according to SMA subtypes. 13\% experienced an improved respiratory and bulbar function, both mainly in SMA type 2.

$29 \%$ (seven cases) reported symptom worsening. In four out of these seven cases, both, deterioration of certain symptoms and improvement of others were reported. Three patients however stated only worsening, thus a disease progression can be assumed (Fig. 2a). Interestingly, 5/7 patients in this symptom worsening group had a SMA 3/4 subtype, who reported decrease in muscle strength, mobility, endurance and independence. Deterioration of bulbar or respiratory function was not reported under nusinersen treatment (Fig. 2b).

The mean objective motor scores, HFMSE [+1.0 (SD 2.6)] and RULM [+ 0.5 (SD 2.3), both increased during a treatment period of maximum 18 months throughout the entire patient cohort. Patients with subjective improvements ( $n=18$, see Fig. 2a), correspondingly developed a greater increase of motor scores, namely HFMSE + 1.3 (SD 2.8) and RULM + 0.7 (SD 1.7)] (Fig. 2c). 


\section{a SETS (cross-sectional)}

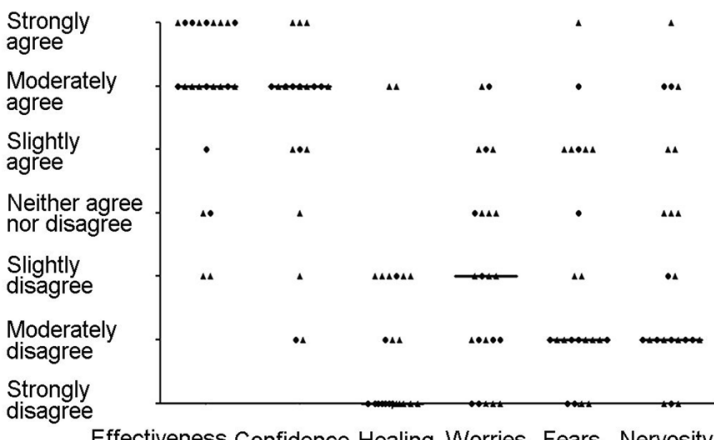

b Expected beneficial outcome

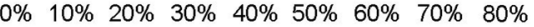
Muscle
strength

Disease

stabilization

Mobility

Endurance

Independence 13

Cure

Bulbar
function

ulbar

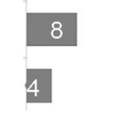

Pie charts
- expected improvements
not expected improvement

SMA type $23 / 4$
C SETS effectiveness (longitudinal)

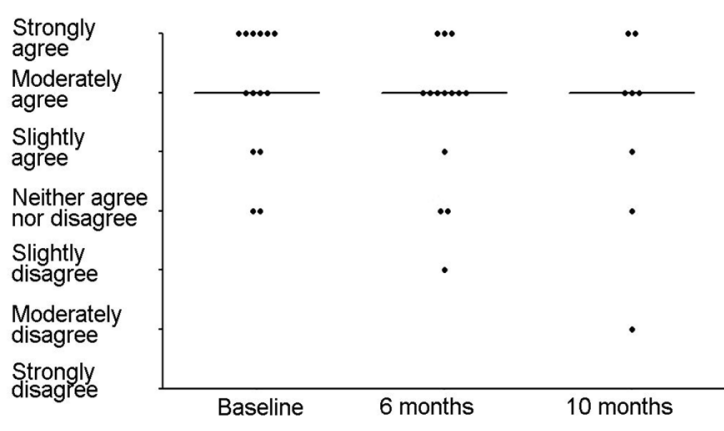

e SETS cure (baseline)

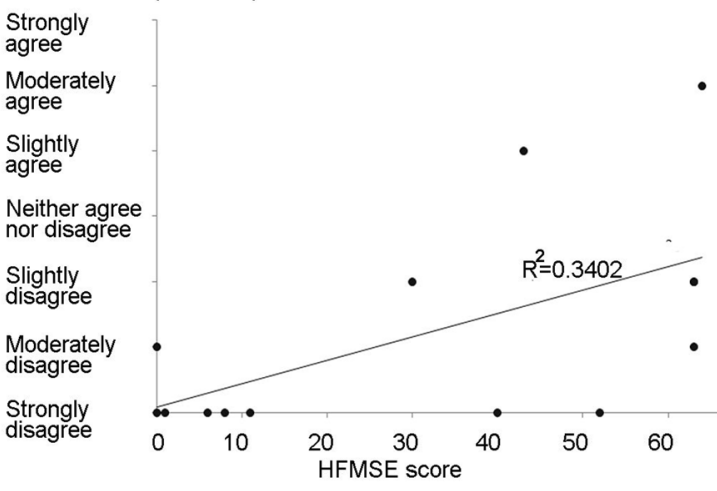

Fig. 1 Treatment expectations of adult SMA patients. a Crosssectional study of the six-item Stanford Expectations of Treatment Scale (SETS) within the first year of nusinersen treatment $(n=23$; 6 -months time point $n=19$, ten months time point $n=4$ ). Dots mark SMA type 3 or 4 patients, triangles mark SMA type 2 patients. The horizontal lines indicate all patients' median for each domain. b Individually expected beneficial outcomes of nusinersen therapy (in $\%$ of $n=24$ patients). Pie charts visualize the proportion of particular expected outcomes in either SMA type $2(n=9)$ or and type $3 / 4$ $(n=15)$ patients. $\mathbf{c}$ Longitudinal analysis of the expectation of nusinersen effectiveness (baseline to month $10 ; n=13$ ). The horizontal

Only the BMI was significantly correlated with disease deterioration $(r=0.474, p=0.019)$ : regression analysis revealed that a higher BMI was significantly associated with more frequent reporting of worsening $\left(R^{2}=0.225\right)$. However, no significant correlation with objective motor d SETS nervousness about side effects (longitudinal)

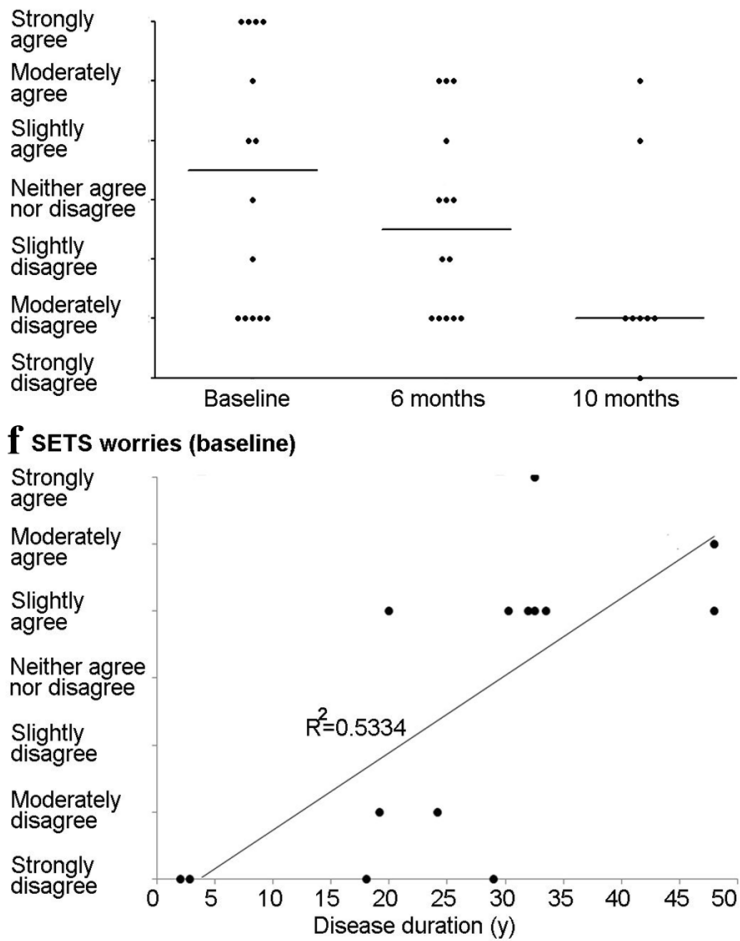

lines indicate the median at each time point. d Longitudinal analysis of patients' nervousness about side effects along with nusinersen therapy (baseline to month $10 ; n=13$ ). Again, the horizontal lines indicate the median at each time point. e The linear regression analysis displays the significant correlation of a higher HFMSE (Hammersmith Functional Motor Scale Expanded) score, thus a milder condition, with an increased expectation of a cure $\left(R^{2}=0.3402, p=0.029\right)$. f The adjustment curve of the linear regression analysis pictures the significant relationship of patients' increased worries about nusinersen treatment to a longer disease duration measured in years $(\mathrm{y})$ $\left(R^{2}=0.5334, p=0.003\right)$

outcomes (HFMSE and RULM) was detected. For age, SMA type, SMN2 copy number, disease duration and ambulatory status or baseline motor scores no significant correlation was found (data not shown). 
a Sum of reported improvement or deterioration per patient

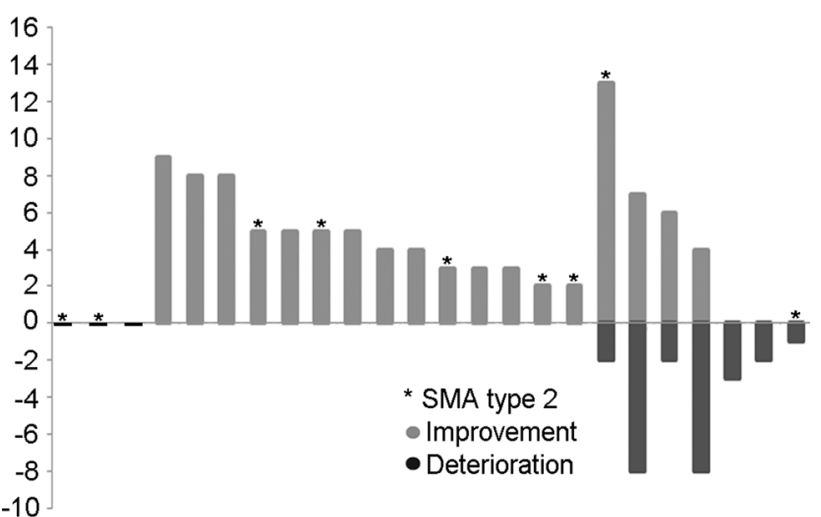

b SMA patients' reported outcomes

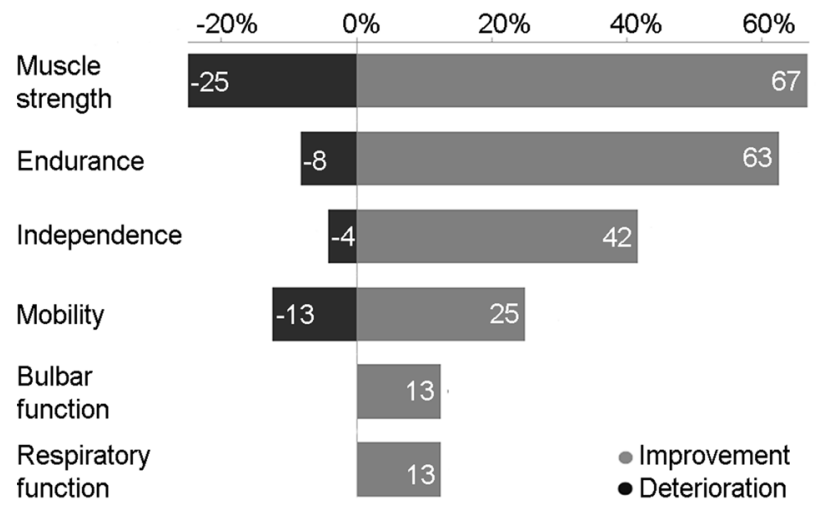

C Motor score changes to baseline

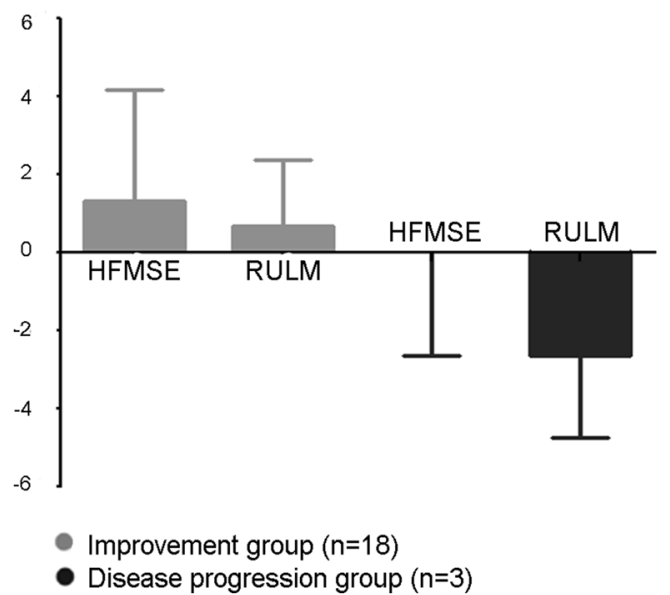

Fig. 2 Patient-reported outcomes (PROs) and quantitatively measured motor scores under ten months of nusinersen treatment. a Sum of reported improved and worsened conditions under nusinersen treatment (each bar indicates one patient). Light columns indicate improvements, dark columns deteriorations. *=SMA type 2 patients. b Ratio of patients who indicated improvement (in \%) and deterioration (in \%) of specific symptoms. Light bars represent improvement, the dark ones deterioration. c Changes in the quantitatively measurable motor scores HFMSE (Hammersmith Functional Motor Scale Expanded) and RULM (Revised Upper Limb Module) under ten months of treatment. Light bars represent patients who indicated subjective improvements $(n=18$; HFMSE mean $+1.3, \mathrm{SD}=2.8$; RULM mean $+0.7, \mathrm{SD}=1.7$ ). Dark bars represent those patients who only stated worsening, which means disease progression $(n=3$; HFMSE mean $0, \mathrm{SD}=2.6$; RULM mean $=-2.7, \mathrm{SD}=2.08)$
Moreover, we did not see any significant influence of pretreatment expectations of nusinersen effectiveness on subjectively experienced outcome (improvement $p=1.00$, worsening $p=0.076$ ) or objective outcome measures (HFMSE $p=0.716$, RULM $p=1.000$ ). Treatment outcome therefore appeared to be not significantly biased by prior expectations.

\section{Discussion}

Altogether, in this study we demonstrated that adult SMA patients had high expectations of treatment effectiveness and high confidence in nusinersen that remained stable during the treatment. Negative expectations (worries, fears, and nervousness about negative effects) were much less frequent and even further decreased during treatment. The most frequently reported expectations were an increase in muscle strength and a disease stabilization, whereas patients with a milder phenotype more often expected a cure of their condition. Analyzes of PROs support the efficacy of this therapy in adult 5q-associated SMA, as a higher proportion of patients (75\%) reported an improvement of their disease status (increase in muscle strength, endurance and independence) compared to those who reported a symptom progression over an evaluation period of ten months. This was supported by an increase in the quantitative motor scores HFMSE (+1.3) and RULM (+0.7). Interestingly, pre-treatment expectations were not found to influence the outcomes under therapy in our cohort.

In 2017, when the first targeted treatment for SMA became available in Europe, placebo-controlled efficacy trials in adult SMA patients were missing. Medical information and outcome expectations were derived from clearly beneficial results in children (up to 12 years) with SMA type 2 and 3 who demonstrated clinically significant improvement in motor function in the HFMSE score over 15 months of treatment [8]. Consistently, in our cohort, $79 \%$ of adult SMA patients expected an increase in muscle strength. Nevertheless, the individual expectations were quite moderate and reflected the rather advanced disease stages decades after symptom onset.

Despite the necessity of intrathecal administration, markedly more positive than negative expectations were expressed by the patients and consistently, hardly a patient declined nusinersen treatment. Fear of negative effects and nervousness seemed to be of minor importance and even decreased within the course of the therapy. These data indicate a high acceptance and good tolerability of this therapy despite the burdensome intrathecal administration and high individual efforts (such as long distances to specialized centers, inpatient treatment, radiation exposure in case of computer tomography (CT)-guided administration and others). Interestingly, patients with a longer disease duration 
reported significantly more often negative pre-treatment expectations. In late-stage SMA, patients have severe thoracolumbar scoliosis [19], thus intrathecal nusinersen injection is substantially more challenging and patients might expect more side effects. In our daily routine and as described by others, CT-guided intrathecal delivery of nusinersen in SMA patients with severe scoliosis has been well established. This approach was shown to be safe and well tolerated [20-24]. However, side effects reported in our cohort and other recently published studies mainly resulted from the lumbar puncture procedure itself and were not directly related to the medication $[24,25]$. The overall low occurrence of side effects and the high level of confidence in nusinersen therapy may underpin our observation of a constant decrease in negative treatment expectations during treatment.

So far, it is not well known to what extent patient expectations influence outcomes. However, pre-treatment expectation has been described as a factor that impacts treatment outcome. Individuals who strongly believe that they will benefit from treatment may be more likely to report benefits, known as placebo effect [13, 17]. Nusinersen has been approved for all SMA patients without limitations regarding the type of disease or patients' age and disease duration; therefore, no placebo (untreated) control population is available in adults. As nusinersen is the first approved therapy for SMA, a placebo effect may be assumed. Our data, however, do not show a significant correlation between pre-treatment positive expectations and beneficial treatment outcome. To note, only 14 adult SMA patients completed the SETS before therapy initiation. Due to this small patient size at least a partially meaningful correlation cannot be fully excluded.

Regarding treatment efficacy, definite conclusions cannot be drawn from this study. We did, however, see indications for a beneficial effect. $75 \%$ of our patients reported clinical improvements such as an increase in muscle strength (67\%), endurance (63\%) and independence (42\%). These improvements were not correlated to any baseline characteristics. Objective motor outcome scores, HFMSE and RULM, revealed the same trend. However, only a three point change in HFMSE is considered as clinically meaningful [16], which apparently stands in discrepancy to the patients' subjectively reported improvement of muscle strength, possibly due to a certain placebo effect. Nonetheless, the natural course of SMA is known to be chronically progressive without spontaneous, even minor, improvements [26-29]. Moreover, the HFMSE does not reflect all relevant muscle functions. Changes in the 3-point scoring system mainly reflect gross motor function changes, as a score of 0 means "unable to perform the task" (i.e. item 1: "unable to sit"), a score of 1 means "perfoms the task with modification/ adaptation/compensation" (i.e. item 1: "needs one hand support to maintain balance for a count of 3") and score of 2 means "performs the task without modification/adaptation/ compensation" (i.e. item 1: "able to sit using no hand support for a count of 3 or more"). Minor improvements, such as an increase in thumb movement, which may have a meaningful impact on a patient's independence and communication/ ability to work, are thus not captured by the HFMSE and also would be missed by the RULM score. Noteworthy, a 3-year follow-up study on nusinersen treatment in later-onset children with SMA and recently published studies conducted in adult SMA patients, observed significant improvements in motor function. In line with our data, these results provide evidence for the long-term benefits of nusinersen in later-onset SMA [11, 30, 31]. In our cohort, however, we also identified three patients who reported a deterioration of symptoms during the treatment (1 SMA type 2 and 2 SMA type 3) in line with a decline in quantitative motor function scores. Two of these patients have withdrawn from treatment so far.

Remarkably, our data demonstrate a significant correlation between BMI and patient-reported clinical worsening $(p=0.019)$. A higher BMI was significantly associated with more frequently reported worsening during nusinersen treatment. Treatment regimen and dosing for adults were adapted from the CHERISH and the ENDEAR trials in infants and children $[7,8,10]$ but might not be sufficient for adult patients with higher body weight. A possible conclusion could be that weight-adjusted treatment regimens might have additional benefits. Treatment effects and body weight, however, did not correlate with HFMSE and RULM scores. Therefore, further studies addressing potential weightdependent treatment response need to be performed.

Overall, the results of our study certainly must be confirmed over a longer time period and in larger patient cohorts. In rare diseases like SMA, this is only feasible within national and international collaborations [12, 32]. Another limitation is that the patient questionnaire used in this study to assess improvement or deterioration of symptoms has not been validated and can therefore not be used for comparisons between different studies. Further, it was not suitable to measure the quality of the reported outcomes but only indicated whether or not patients experienced improvement or worsening. Thus, standardized questionnaires for adult SMA patients are urgently needed. Our study demonstrates the advantages of PROs: small (subclinical) changes are detected more sensitively instead of being missed in assessments which only address gross motor changes. They might, in particular, be more sensitive in more severely handicapped patients in advanced disease stages. Moreover, PROs can be used as a quick and easy bedside test without special equipment or training.

To summarize, we systematically assessed the expectations and PROs of adult 5q-associated SMA patients under nusinersen treatment for the first time. We were able to demonstrate mainly positive expectations and a high level 
of confidence under therapy. Moreover, our data indicate the efficacy of nusinersen in adult, often severely affected patients with SMA types 2 and $3 / 4$ and show that positive expectations were met in the vast majority of cases. Besides, we suggest PROs as an important measure to assess treatment effects. A multicenter approach and longer observation periods are needed for further confirmation.

Acknowledgement Open Access funding provided by Projekt DEAL. The authors wish to thank all patients for participating in this study and the trained therapists Friederike Bonetti, Kerstin Reckmann and Daniela Winkler for performing the motor function testing.

Author contributions AO wrote the manuscript, planned and designed the study, performed data collection and interpretation and coordinated the study. GR supported in manuscript writing, collected data and performed data interpretation. MK, LM, CB and FW were responsible for local data collection and critically revised the manuscript. LP critically revised the manuscript. KK and SK were involved in coordination of the study and critically revised the manuscript. SP planned the study, was involved in coordination of the study, was responsible for local data collection and contribution, and critically revised the manuscript. OSK was involved in study design and study planning, data collection and interpretation, supervision and writing of the manuscript.

Funding German Research Foundation (DFG), PRACTIS-Clinician Scientist Program of Hannover Medical School (ME 3696/3-1, grant to A. Osmanovic). German Neuromuscular Society (Deutsche Gesellschaft fuer Muskelkranke (DGM e.V.)), Federal Ministry of Education and Research (BMBF), German Israeli Foundation for Scientific Research and Development, EU Joint Programme for Neurodegenerative Disease Research (grants to S. Petri). Hannover Medical School Young Faculty Program for Clinician Scientists (grant to O. Schreiber-Katz).

\section{Compliance with ethical standards}

Conflicts of interest AO received honoraria from the Deutsche Gesellschaft fuer Muskelkranke (DGM e.V.) and Biogen. GR and MK received travel funding from Biogen $\mathrm{GmbH}$. LM, CB, FW and SK report no disclosures. LP received travel grants and/or honoraria for lectures from Allergan, Ipsen, Merz. KK received travel grants and/or honoraria for lectures from Allergan, Biogen, Ipsen, Lilly, Novartis, Merz, Teva. SP received honoraria from Biogen, Cytokinetics, Inc., Desitin Pharma, Novartis, Roche, Teva. OSK received scientific grants, travel grants and/or honoraria from the German Neuromuscular Society (Deutsche Gesellschaft fuer Muskelkranke (DGM e.V.)), Novartis, Biogen, Jain Foundation.

Ethical approval The study has been approved by the local ethics review board at Hannover Medical School and has, therefore, been performed in accordance with the ethical standards laid down in the 1964 Declaration of Helsinki and its later amendments. All patients gave their written informed consent before entering the study.

Open Access This article is licensed under a Creative Commons Attribution 4.0 International License, which permits use, sharing, adaptation, distribution and reproduction in any medium or format, as long as you give appropriate credit to the original author(s) and the source, provide a link to the Creative Commons licence, and indicate if changes were made. The images or other third party material in this article are included in the article's Creative Commons licence, unless indicated otherwise in a credit line to the material. If material is not included in the article's Creative Commons licence and your intended use is not permitted by statutory regulation or exceeds the permitted use, you will need to obtain permission directly from the copyright holder. To view a copy of this licence, visit http://creativecommons.org/licenses/by/4.0/.

\section{References}

1. Hoy SM (2017) Nusinersen: first global approval. Drugs 77(4):473-479. https://doi.org/10.1007/s40265-017-0711-7

2. D'Amico A, Mercuri E, Tiziano FD, Bertini E (2011) Spinal muscular atrophy. Orphanet J Rare Dis 6:71. https://doi. org/10.1186/1750-1172-6-71

3. Kolb SJ, Kissel JT (2015) Spinal muscular atrophy. Neurol Clin 33(4):831-846. https://doi.org/10.1016/j.ncl.2015.07.004

4. Swoboda KJ, Prior TW, Scott CB, McNaught TP, Wride MC, Reyna SP, Bromberg MB (2005) Natural history of denervation in SMA: relation to age, SMN2 copy number, and function. Ann Neurol 57(5):704-712. https://doi.org/10.1002/ana.20473

5. Lefebvre S, Burglen L, Reboullet S, Clermont O, Burlet P, Viollet L, Benichou B, Cruaud C, Millasseau P, Zeviani M et al (1995) Identification and characterization of a spinal muscular atrophy-determining gene. Cell 80(1):155-165. https://doi. org/10.1016/0092-8674(95)90460-3

6. Crawford TO, Paushkin SV, Kobayashi DT, Forrest SJ, Joyce CL, Finkel RS, Kaufmann P, Swoboda KJ, Tiziano D, Lomastro R, Li RH, Trachtenberg FL, Plasterer T, Chen KS, Pilot Study of Biomarkers for Spinal Muscular Atrophy Trial G (2012) Evaluation of SMN protein, transcript, and copy number in the biomarkers for spinal muscular atrophy (BforSMA) clinical study. PLoS ONE 7(4):e33572. https://doi.org/10.1371/journ al.pone. 0033572

7. Finkel RS, Mercuri E, Darras BT, Connolly AM, Kuntz NL, Kirschner J, Chiriboga CA, Saito K, Servais L, Tizzano E, Topaloglu H, Tulinius M, Montes J, Glanzman AM, Bishop K, Zhong ZJ, Gheuens S, Bennett CF, Schneider E, Farwell W, De Vivo DC, Group ES (2017) Nusinersen versus Sham Control in infantileonset spinal muscular atrophy. N Engl J Med 377(18):1723-1732. https://doi.org/10.1056/NEJMoa1702752

8. Mercuri E, Darras BT, Chiriboga CA, Day JW, Campbell C, Connolly AM, Iannaccone ST, Kirschner J, Kuntz NL, Saito K, Shieh PB, Tulinius M, Mazzone ES, Montes J, Bishop KM, Yang Q, Foster R, Gheuens S, Bennett CF, Farwell W, Schneider E, De Vivo DC, Finkel RS, Group CS (2018) Nusinersen versus Sham control in later-onset spinal muscular atrophy. N Engl J Med 378(7):625-635. https://doi.org/10.1056/NEJMoa1710504

9. Bennett CF, Baker BF, Pham N, Swayze E, Geary RS (2017) Pharmacology of antisense drugs. Annu Rev Pharmacol Toxicol 57:81-105. https://doi.org/10.1146/annurev-pharmtox-01071 6-104846

10. Finkel RS, Chiriboga CA, Vajsar J, Day JW, Montes J, De Vivo DC, Yamashita M, Rigo F, Hung G, Schneider E, Norris DA, Xia S, Bennett CF, Bishop KM (2016) Treatment of infantile-onset spinal muscular atrophy with nusinersen: a phase 2, open-label, dose-escalation study. Lancet 388(10063):3017-3026. https://doi. org/10.1016/S0140-6736(16)31408-8

11. Hagenacker T, Wurster CD, Gunther R, Schreiber-Katz O, Osmanovic A, Petri S, Weiler M, Ziegler A, Kuttler J, Koch JC, Schneider I, Wunderlich G, Schloss N, Lehmann HC, Cordts I, Deschauer M, Lingor P, Kamm C, Stolte B, Pietruck L, Totzeck A, Kizina K, Monninghoff C, von Velsen O, Ose C, Reichmann H, Forsting M, Pechmann A, Kirschner J, Ludolph AC, Hermann 
A, Kleinschnitz C (2020) Nusinersen in adults with 5q spinal muscular atrophy: a non-interventional, multicentre, observational cohort study. Lancet Neurol 19(4):317-325. https://doi. org/10.1016/S1474-4422(20)30037-5

12. Pechmann A, Konig K, Bernert G, Schachtrup K, Schara U, Schorling D, Schwersenz I, Stein S, Tassoni A, Vogt S, Walter MC, Lochmuller H, Kirschner J (2019) SMArtCARE—a platform to collect real-life outcome data of patients with spinal muscular atrophy. Orphanet J Rare Dis 14(1):18. https://doi.org/10.1186/ s13023-019-0998-4

13. Linde K, Witt CM, Streng A, Weidenhammer W, Wagenpfeil S, Brinkhaus B, Willich SN, Melchart D (2007) The impact of patient expectations on outcomes in four randomized controlled trials of acupuncture in patients with chronic pain. Pain 128(3):264-271. https://doi.org/10.1016/j.pain.2006.12.006

14. Colagiuri B (2010) Participant expectancies in double-blind randomized placebo-controlled trials: potential limitations to trial validity. Clin Trials 7(3):246-255. https://doi.org/10.1177/17407 74510367916

15. Mazzone ES, Mayhew A, Montes J, Ramsey D, Fanelli L, Young SD, Salazar R, De Sanctis R, Pasternak A, Glanzman A, Coratti G, Civitello M, Forcina N, Gee R, Duong T, Pane M, Scoto M, Pera MC, Messina S, Tennekoon G, Day JW, Darras BT, De Vivo DC, Finkel R, Muntoni F, Mercuri E (2017) Revised upper limb module for spinal muscular atrophy: development of a new module. Muscle Nerve 55(6):869-874. https://doi.org/10.1002/ mus. 25430

16. Pera MC, Coratti G, Forcina N, Mazzone ES, Scoto M, Montes J, Pasternak A, Mayhew A, Messina S, Sframeli M, Main M, Lofra RM, Duong T, Ramsey D, Dunaway S, Salazar R, Fanelli L, Civitello M, de Sanctis R, Antonaci L, Lapenta L, Lucibello S, Pane M, Day J, Darras BT, De Vivo DC, Muntoni F, Finkel R, Mercuri E (2017) Content validity and clinical meaningfulness of the HFMSE in spinal muscular atrophy. BMC Neurol 17(1):39. https://doi.org/10.1186/s12883-017-0790-9

17. Younger J, Gandhi V, Hubbard E, Mackey S (2012) Development of the Stanford expectations of treatment scale (SETS): a tool for measuring patient outcome expectancy in clinical trials. Clin Trials 9(6):767-776. https://doi.org/10.1177/1740774512465064

18. TREAT-NMD Neuromuscular Network (2012). https://www.treat -nmd.de/register/. Accessed 27 Apr 2020

19. Fujak A, Raab W, Schuh A, Richter S, Forst R, Forst J (2013) Natural course of scoliosis in proximal spinal muscular atrophy type II and IIIa: descriptive clinical study with retrospective data collection of 126 patients. BMC Musculoskelet Disord 14:283. https://doi.org/10.1186/1471-2474-14-283

20. Bortolani S, Stura G, Ventilii G, Vercelli L, Rolle E, Ricci F, Bergui M, Mongini T (2019) Intrathecal administration of nusinersen in adult and adolescent patients with spinal muscular atrophy and scoliosis: transforaminal versus conventional approach. Neuromuscul Disord 29(10):742-746. https://doi.org/10.1016/j. nmd.2019.08.007

21. Wurster CD, Winter B, Wollinsky K, Ludolph AC, Uzelac Z, Witzel S, Schocke M, Schneider R, Kocak T (2019) Intrathecal administration of nusinersen in adolescent and adult SMA type 2 and 3 patients. J Neurol 266(1):183-194. https://doi.org/10.1007/ s00415-018-9124-0

22. Oldenburg D, Guberina N, Stolte B, Kizina K, Stenzel E, Radbruch A, Kleinschnitz C, Hagenacker T, Forsting M, Monninghoff C (2019) Radiation exposure of image-guided intrathecal administration of nusinersen to adult patients with spinal muscular atrophy. Neuroradiology 61(5):565-574. https://doi.org/10.1007/ s00234-019-02189-x

23. Sansone VA, Albamonte E, Salmin F, Casiraghi J, Pirola A, Bettinelli M, Rao F, Mancini L, Tovaglieri N, Fedeli F, Stoia P, Heinen M, Cozzi V, Carraro E, Lunetta C, Di Bari A, Mercuri E,
Italian EAPwg (2019) Intrathecal nusinersen treatment for SMA in a dedicated neuromuscular clinic: an example of multidisciplinary and integrated care. Neurol Sci 40(2):327-332. https://doi. org/10.1007/s10072-018-3622-9

24. Stolte B, Totzeck A, Kizina K, Bolz S, Pietruck L, Monninghoff C, Guberina N, Oldenburg D, Forsting M, Kleinschnitz C, Hagenacker T (2018) Feasibility and safety of intrathecal treatment with nusinersen in adult patients with spinal muscular atrophy. Ther Adv Neurol Disord 11:1756286418803246. https://doi. org/10.1177/1756286418803246

25. Hache M, Swoboda KJ, Sethna N, Farrow-Gillespie A, Khandji A, Xia S, Bishop KM (2016) Intrathecal injections in children with spinal muscular atrophy: nusinersen clinical trial experience. J Child Neurol 31(7):899-906. https://doi.org/10.1177/0883073815 627882

26. Kaufmann P, McDermott MP, Darras BT, Finkel RS, Sproule DM, Kang PB, Oskoui M, Constantinescu A, Gooch CL, Foley AR, Yang ML, Tawil R, Chung WK, Martens WB, Montes J, Battista V, O'Hagen J, Dunaway S, Flickinger J, Quigley J, Riley S, Glanzman AM, Benton M, Ryan PA, Punyanitya M, Montgomery MJ, Marra J, Koo B, De Vivo DC, Muscle Study G, Pediatric Neuromuscular Clinical Research Network for Spinal Muscular A (2012) Prospective cohort study of spinal muscular atrophy types 2 and 3. Neurology 79(18):1889-1897. https://doi.org/10.1212/ WNL.0b013e318271f7e4

27. Wadman RI, Wijngaarde CA, Stam M, Bartels B, Otto LAM, Lemmink HH, Schoenmakers M, Cuppen I, van den Berg LH, van der Pol WL (2018) Muscle strength and motor function throughout life in a cross-sectional cohort of 180 patients with spinal muscular atrophy types 1c-4. Eur J Neurol 25(3):512-518. https ://doi.org/10.1111/ene.13534

28. Montes J, McDermott MP, Mirek E, Mazzone ES, Main M, Glanzman AM, Duong T, Young SD, Salazar R, Pasternak A, Gee R, De Sanctis R, Coratti G, Forcina N, Fanelli L, Ramsey D, Milev E, Civitello M, Pane M, Pera MC, Scoto M, Day JW, Tennekoon G, Finkel RS, Darras BT, Muntoni F, De Vivo DC, Mercuri E (2018) Ambulatory function in spinal muscular atrophy: age-related patterns of progression. PLoS ONE 13(6):e0199657. https://doi. org/10.1371/journal.pone.0199657

29. Mercuri E, Finkel R, Montes J, Mazzone ES, Sormani MP, Main M, Ramsey D, Mayhew A, Glanzman AM, Dunaway S, Salazar R, Pasternak A, Quigley J, Pane M, Pera MC, Scoto M, Messina S, Sframeli M, Vita GL, D’Amico A, van den Hauwe M, Sivo S, Goemans N, Kaufmann P, Darras BT, Bertini E, Muntoni F, De Vivo DC (2016) Patterns of disease progression in type 2 and 3 SMA: implications for clinical trials. Neuromuscul Disord 26(2):126-131. https://doi.org/10.1016/j.nmd.2015.10.006

30. Darras BT, Chiriboga CA, Iannaccone ST, Swoboda KJ, Montes J, Mignon L, Xia S, Bennett CF, Bishop KM, Shefner JM, Green AM, Sun P, Bhan I, Gheuens S, Schneider E, Farwell W, De Vivo DC, Groups I-CI-CS (2019) Nusinersen in later-onset spinal muscular atrophy: Long-term results from the phase 1/2 studies. Neurology 92(21):e2492-e2506. https://doi.org/10.1212/WNL.00000 00000007527

31. Walter MC, Wenninger S, Thiele S, Stauber J, Hiebeler M, Greckl E, Stahl K, Pechmann A, Lochmuller H, Kirschner J, Schoser B (2019) Safety and treatment effects of nusinersen in longstanding adult 5q-SMA type 3-a prospective observational study. J Neuromuscul Dis 6(4):453-465. https://doi.org/10.3233/JND-190416

32. Bladen CL, Thompson R, Jackson JM, Garland C, Wegel C, Ambrosini A, Pisano P, Walter MC, Schreiber O, Lusakowska A, Jedrzejowska M, Kostera-Pruszczyk A, van der Pol L, Wadman RI, Gredal O, Karaduman A, Topaloglu H, Yilmaz O, Matyushenko V, Rasic VM, Kosac A, Karcagi V, Garami M, Herczegfalvi A, Monges S, Moresco A, Chertkoff L, Chamova T, Guergueltcheva V, Butoianu N, Craiu D, Korngut L, Campbell 
C, Haberlova J, Strenkova J, Alejandro M, Jimenez A, Ortiz GG, Enriquez GV, Rodrigues M, Roxburgh R, Dawkins H, Youngs L, Lahdetie J, Angelkova N, Saugier-Veber P, Cuisset JM, Bloetzer C, Jeannet PY, Klein A, Nascimento A, Tizzano E, Salgado D, Mercuri E, Sejersen T, Kirschner J, Rafferty K, Straub V, Bushby
K, Verschuuren J, Beroud C, Lochmuller H (2014) Mapping the differences in care for 5,000 spinal muscular atrophy patients, a survey of 24 national registries in North America. Australasia and Europe J Neurol 261(1):152-163. https://doi.org/10.1007/s0041 5-013-7154-1 